\title{
A Narrative Analysis of Basic Income Pilots from an Ontarian Perspective
}

\author{
Spencer Bridgman ${ }^{*}$, Ryerson University
}

\begin{abstract}
The following is a research analysis paper on the Ontario basic income pilot and basic income projects more generally. This analysis will be conducted using a narrative lens. When policies are created or cancelled there is often a narrative that plays a significant role in validating the process. In this paper, the narratives that accompanied the creation and cancellation of Ontario's basic income pilotrespectively referred to as the 'creation' and 'cancellation narratives'-are unpacked. The creation narrative states that basic income projects will reduce poverty, while the cancellation narrative states that basic income projects unjustly redistribute wealth through raising taxes. These narratives are also present in other basic income pilots; two of these are also analyzed in this paper, namely Finland and Manitoba's basic income pilots. The paper concludes with a recommendation for policymakers who are advancing basic income projects in the future. Policymakers should advance a metanarrative that bridges the creation and cancellation narratives. This metanarrative would frame basic income projects as reducing poverty without unjustly redistributing wealth. Such a narrative can be used to advance basic income projects that are more resilient than projects analysed in this paper.
\end{abstract}

Keywords: Basic income, Narrative analysis, Metanarrative, Ontario, Pilot

\section{Résumé}

Cette recherche porte sur le projet pilote de revenu de base de l'Ontario et autres projets de ce type. Cette analyse sera menée dans une optique narrative: lorsque des politiques sont créées ou annulées, il y a souvent un récit qui servent à valider ce processus. Nous étudions les récits qui ont accompagné la création et l'annulation du projet pilote de revenu de base de l'Ontario - appelés respectivement "récits de création » et " récits d'annulation ». Le récit de création indique que les projets de revenu de base réduiront la pauvreté, tandis que le récit d'annulation indique que ces projets redistribuent injustement la richesse en augmentant les impôts. Ces récits sont également présents dans d'autres projets pilotes ; deux d'entre eux, ceux de la Finlande et du Manitoba, sont également analysés dans ce document. Ce travail se termine par une recommandation à l'intention des décideurs politiques qui feront avancer de tels projets pilotes à l'avenir, soit de proposer une métanarrative reliant les récits de création et d'annulation. Cette métanarrative permettrait de présenter les projets de revenu de base comme des projets de réduction de la pauvreté sans redistribution injuste de la richesse. Un tel récit peut être utilisé pour faire avancer des projets de revenu de base plus résilients que ceux analysés dans ce document.

Mots-clés : Revenu de base, Analyse narrative, Métanarrative, Ontario, Projet pilote

\footnotetext{
*Biography:

Spencer Bridgman recently completed a Master of Arts in Public Policy and Administration program at Ryerson University. He previously graduated with an Honours Bachelor of Arts degree from Wilfrid Laurier University and a Master of Arts degree in Philosophy from University of Toronto. His primary interests lie in urban governance, transportation policy, and economic cooperation. Spencer is motivated by the aim to do as much good as possible with his career by researching and developing policies that positively impact a large number of people. Outside of academia, Spencer is an avid traveller and has visited just over twenty countries in his life, including spending the better part of a year teaching English in Thailand.

Biographie:

Spencer Bridgman a récemment complété une maîtrise en administration et politiques publiques à l'Université Ryerson. II avait auparavant obtenu un baccalauréat ès arts avec distinction de l'Université Wilfrid Laurier et une maîtrise en philosophie de l'Université de Toronto. II s'intéresse à la gouvernance urbaine, aux politiques du transport et à la coopération économique. Spencer souhaite rechercher et développer des politiques impactant positivement un grand nombre de personnes. En dehors du milieu universitaire, Spencer est un fervent voyageur qui a visité plus de vingt pays dans sa vie, incluant le passage d'une année presque entière à enseigner l'anglais en Thaïlande.
} 


\section{Introduction}

The Ontario basic income pilot was implemented in April of 2018 and was scheduled to run for three years when it was abruptly cancelled in March of 2019. Since then, there has been little scholarly research completed on the project and even less attention has been given to its connection to other basic income projects. This paper will help fill in this gap in the literature. The focus of this paper is on analyzing the combatting narratives behind the creation and cancellation of the Ontario basic income pilot and how these narratives can be reconciled in future basic income projects in the form of a metanarrative. To advance this analysis, I will first explain the structure of Ontario's pilot and excavate the narratives behind the project's creation and cancellation. Next, I will support the pervasiveness of these narratives in basic income projects by looking at two other basic income pilots whose creation and cancellations mirror Ontario's. Lastly, I will unpack the metanarrative that bridges the creation and cancellation narratives. This metanarrative can be used by policymakers to advance basic income projects in the future that are less susceptible to the cancellation narrative.

Before diving into the particulars of Ontario's basic income pilot, a brief explanation of what a "basic income'1 entails is in order. A basic income is an unconditional cash transfer by the government to all or some of its citizens. The word 'unconditional' is key here and is what differentiates basic income from social welfare programs like employment insurance (EI). With $\mathrm{El}$ in Canada for instance, the cash transfer is conditional on the person losing their job "through no fault of [their] own", them "actively looking for work", and a couple other conditions (Canada, 2019). The only requirement that is usually ${ }^{2}$ in place for a basic income is that one's income is below a certain amount. If one meets this requirement then one receives the basic income.

For Ontario's pilot, "participants [had to be] 18 to 64 [and] living on low income. Payments [were] based on 75 per cent of Statistics Canada's low-income measure. Single individuals receive[d] $\$ 16,989$ less 50 per cent of any earned income; couples receive[d] $\$ 24,027$ less 50 per cent of any combined earned income" (Parliamentary Budget Office, 2018, p. 5). If the participant had been receiving Ontario Works or Ontario Disability Support Program transfers, then these transfers were replaced by the basic income transfer (Parliamentary Budget Office, 2018, p. 5). Participants were chosen randomly from Hamilton, Thunder Bay, and Lindsay communities (Ontario, 2017). To summarize, it proposed an unconditional basic income to citizens living below a certain income and replaced certain conditional transfers they had previously received. With the structure of the program in place, it is now time to examine the narrative that justified the creation of the project.

\section{The Ontario Basic Income Pilot Creation Narrative}

I will be drawing on the notion of a policy narrative from Michel J. G. van Eeten's paper 'Narrative Policy Analysis' (van Eeten, 2007). A narrative is a story that can "[stabilize] the assumptions for policymaking in the face of the issue's uncertainty, complexity or polarization." (van Eeten, 2007, p. 251). Such a narrative is necessary to underpin a basic income project, which has elements of uncertainty, complexity, and the potential to polarize. A narrative is validation for the policy in the face of these elements and can be attributed to "a group, an organization, or even a coalition of organizations" (van Eeten, 2007, p. 253). Since the Ontario Liberal government created the pilot, I will attempt to "excavate the narrative foundations" this organization advanced for the program's creation (van Eeten, 2007, p. 252). This will be referred to as the 'creation narrative'. The word "excavate" is key here because the uncovering of a narrative often reveals "hidden ideological assumptions" that may not be explicitly communicated by the actor (van Eeten, 2007, p. 252).

In the case of this narrative, the Ontario government's assumptions are easy to uncover. In the official news release Ontario announced that the pilot aimed "to test a growing view at home and abroad that basic income could provide a new approach to reducing poverty in a sustainable way"

\footnotetext{
${ }^{1}$ I will use the term 'basic income' instead of 'guaranteed annual income' because it correlates with Ontario's recent use of the concept.

${ }^{2}$ Notably, this is not always the case. The idea of implementing a basic income that every citizen receives has been gaining momentum. This is evidenced by its inclusion in the platforms of Democratic Nominee Andrew Yang in the USA and Liberal Leader Nominee Alvin Tedjo in Ontario.
} 
(Ontario, 2017). The narrative articulated here is that the Ontario government wanted to reduce poverty in Ontario and basic income was a plausible way to accomplish this. This sentiment is also echoed with more narrative heft in Hugh Segal's influential discussion paper on the pilot in which he asserted that, "[a] Basic Income pilot would be a test of a 'new path' on poverty reduction, one that is based on humanity, and on the respect for the privacy and dignity of all Ontarians, whether poor or not" (Segal, 2016). This is a more eloquent articulation of the same creation narrative advanced by the Ontario government. At the center of the statement is the focus on poverty reduction as the project's goal. With the creation narrative established, it is now time to turn to the narrative that facilitated the project's cancellation. This will be referred to as the 'cancellation narrative'.

\section{The Ontario Basic Income Pilot Cancellation Narrative}

The cancellation of the project was announced by the recently elected Progressive Conservative Party of Ontario on August 31, 2018. Four months into the projected three-year pilot, Lisa MacLeod-Minister of Children, Community and Social Services-revealed that the project would be wound down over the coming months with the last transfers divvied out by March 31, 2019 (Ontario, 2018). Unlike the creation narrative, some excavation is needed to reveal the narrative behind the Ontario government's cancellation of the project. The narrative advanced in the official news release was that,

A research project that helps less than four thousand people is not the answer and provides no hope to the nearly two million Ontarians who are trapped in the cycle of poverty... The research project had an extraordinary cost for Ontario taxpayers which, according to the Ministry of Finance, would require increasing the HST from 13 per cent to 20 per cent if implemented across the province (Ontario, 2018).

The government's reasoning here is somewhat difficult to follow. The former premise asserts that the pilot in itself cannot reduce the poverty of those not included in the pilot. This is obvious, and is not a valid justification for its cancellation. It was always understood that poverty could be reduced on an Ontario-wide scale only if the pilot was successful and then implemented on that scale. The logic advanced in the second sentence of the excerpt is also odd. It asserts that the cost of the pilot is "extraordinary" and then justifies this claim by referring to the cost of a province wide basic income implementation. The cost of completing the pilot would not require increasing the HST, as evidenced by the fact that HST was not increased in the budgeting for the pilot. To use this as justification for its cancellation is confusing and disingenuous. Thus, this statement does not provide a cogent narrative for the cancellation of the pilot. What it does provide is a starting point from which to excavate the underlying government narrative against basic income projects more generally.

To uncover this narrative one needs to focus on the part of the news release that targets the implementation of province wide basic income and then expound this narrative using sources that are less guarded than the Ontario government. Implementing a provincial basic income "would require increasing the HST from 13 per cent to 20 per cent if implemented across the province" (Ontario, 2018). The message here is that the program will cost you money. You should not have to pay more taxes to reduce poverty. The 'you' in this narrative refers to the populace, the taxpayers, the everyday Canadian, and going forward can be understood as a broad term for what is perhaps most commonly referred to as 'the people'. The same narrative is present in Brian Lee Crowley and Sean Speer's recent McDonald-Laurier Institute report on basic income projects in Canada. The report states that implementing a national basic income will require raising "[a]n additional $\$ 44$ billion in annual revenue [which is] is roughly the equivalent of doubling the GST from 5 percent to 10 percent [and] is likely politically unpalatable" (Crowley and Speer, 2018, p. 14). This parallels the Ontario government's narrative that basic income projects are faulty because they cost the people money. Nowhere is this narrative more honestly articulated than by a commenter on a Toronto Sun article written by Crowley and Speer titled 'Why Ontario was right to cancel the basic income project' (Crowley and Speer, 2018). The commenter writes, "[t]aking money from someone who earned it and giving it to someone who didn't is theft [8 likes]" (Crowley and Speer, 2018). Contained in these statements is the narrative validating the Progressive Conservative government's cancellation of the basic income pilot: the 
people should not have to give up more of their hard-earned money through taxes to reduce poverty. This is the cancellation narrative.

Those familiar with the basic income conversation may feel at this point that this cancellation narrative runs up quite close with another narrative often advanced in opposition to basic income projects, namely that such programs disincentivize people from working. This can be thought of as the 'disincentive narrative'. There is a growing body of evidence that this is not the case ${ }^{3}$, but regardless, this is not the narrative underpinning the cancellation of the basic income projects. It is not a hypothetical increase in unemployed people that leads to basic income projects failing; it is unemployed people who are receiving your money. The disincentive narrative is advanced because it seems less callous than the cancellation narrative, and can therefore function as a screen for those who endorse the cancellation narrative, but are apprehensive to do so publicly. This is why organizations like the Ontario government seem undeterred when presented with empirical evidence supporting the lack of connection between basic income and worker disincentive. They are undeterred because it is not their real reason for cancelling the project. Their real reason is that basic income will increase taxes and thus unfairly impact you the people. It is now time to analyse how this cancellation narrative can be guarded against.

This can be accomplished through providing a metanarrative. To provide a metanarrative, one must "develop a new narrative that takes into account the existing narratives, but at the same time is more amenable to deliberation or policy making" (van Eeten, 2007, p. 255). In the case at hand, this narrative must reconcile the aspirations of the creation narrative with the reservations of the cancellation narrative so that basic income projects are resilient to the latter. The development of such a metanarrative will only be useful if there is reason to believe that the narratives I have identified in Ontario's pilot are emblematic of a larger pattern in how basic income projects are created and cancelled. If Ontario's cancellation is unique, then no lessons can be learned from it when constructing future narratives around basic income projects. This is not the case. The Ontario pilot's creation-and more importantly its cancellation-follows a narrative structure present in many other basic income projects. I will briefly look at two of these projects to draw out this point.

\section{Other Basic Income Pilots with the Creation and Cancellation Narratives}

The first is Mincome. This was a basic income pilot that was carried out in Manitoba between 1974 and 1979 (Forget, 2011, p. 284). Like Ontario's pilot, it provided unconditional cash transfers to low-income families in three communities. Also like Ontario's pilot, it was implemented with ambitious goals and wound down with seeming indifference to these goals. The narrative around the pilot's creation had both explicit and implicit goals. Explicitly, Mincome's goal was to "measure the effect of various combinations of guaranteed income levels and tax-back rates on the labour supply response of the recipients of guaranteed annual income payments" (Farthing, 1991, p. 160). In other words, it aimed to test if basic income payments disincentivized workers. Implicit in this goal is the assumption that if the program was shown not to disincentivize workers, then it could be an effective way to reduce poverty on a larger scale. This was articulated explicitly in November 1970 when "the Department of National Health and Welfare emphasized the potential of a guaranteed income as an anti-poverty measure" (Hum and Simpson, 1993, p. 443). Thus, the narrative behind the creation of Mincome is comparable to the narrative behind the creation of Ontario's pilot: both aimed to measure particular effects of basic income with the larger goal of reducing poverty.

"The Mincome project died a quiet death in 1979" (Hum and Simpson, 1993, p. 445). As was the case with Ontario's pilot, uncovering the narrative that justified Mincome's death requires some digging. Despite both the federal and provincial government's funding of Mincome, no news release was made by either level to justify the termination of the project. However, if one digs a little deeper, a cancellation narrative similar to the one observed in Ontario can be found at both the provincial and federal level. At the provincial level, there were dissenting Manitoban MPPs like Robert Wilson who

\footnotetext{
${ }^{3}$ Basic income pilots in Manitoba, Finland, Namibia, India, and Stockton have all found that cash transfers disincentivizing effects were minimal or nonexistent, and studies on unconditional cash transfers more generally have arrived at the same conclusion. (Marinescu, 2017)
} 
exclaimed in the Legislative Assembly that "as a taxpayer" the project was not worth 17 million dollars because "we don't have that many poor people in Manitoba compared to the Maritimes; compared to some of the hovels in Montreal" (Legislative Assembly of Manitoba, 1979, p. 2130). The obvious implication here is that poverty reduction is not a major issue, and thus, should not come at an increased price to the taxpaying people. At the federal level, then-Prime Minister Pierre Elliot Trudeau voiced as early as 1973 that "middle-clash backlash at higher taxes" was the reason he could not seriously entertain more poverty reduction programs like a nation-wide guaranteed annual income (Malling, 1973, p. A8). The narrative is clear: Mincome was cancelled because poverty reduction at the cost of raising taxes was not seen as worthwhile. ${ }^{4}$ Thus, the creation and cancellation narratives in the case of Mincome are comparable to those found in Ontario's pilot. Let us now turn to a more recent international basic income project that also exemplifies this narrative pattern.

In 2015, Finland gained the world's attention by announcing its own basic income experiment. The aforementioned Hugh Segal cited Finland's experiment as an example of the broadening of support worldwide for basic income projects. "Ontario is definitely not alone in pursuing a better way to reduce poverty", he confidently asserted (Segal, 2016). The narrative that precipitated the experiment's creation is one that should sound familiar. It aimed to test specifics-namely whether or not a basic income "could further increase the labour supply"-while also pursuing broader aims to "make the social security system in Finland more inclusive" (Ministry of Social Affairs and Health, 2019 , p. 3). The latter goal fits the creation narrative observed in the previous pilots: a more inclusive social security system is one in which more members of the public are lifted out of poverty.

The Finnish experiment was implemented from 2017 to 2018 . The preliminary results from the first year of the experiment were announced in February of 2019 and were generally positive. The report found that "there [was] no statistically significant difference between the groups as regards employment. However, the survey results showed significant differences between the groups for different aspects of wellbeing"5 (Ministry of Social Affairs and Health, 2019, p. 30). Unfortunatelymonths before these preliminary results were released-the Finnish government had already determined that it would not be moving forward with further funding for the experiment (Goodman, 2018). As was the case with the Mincome pilot, there has not been an official news release from the government regarding its cancellation of the project. New York Times reporter Peter Goodman reasons that the cancellation is "a reflection of public discomfort with the idea of dispensing government largess free of requirements that its recipients seek work" and that "[m]any people in Finland chafe at the idea of handing out cash without requiring that people work" (Goodman, 2018). Once again, the cancellation narrative that was observed in the two Canadian basic income pilots emerges. The Finnish experiment lost support because the people did not want to pay more to reduce poverty.

\section{Identifying a Metanarrative}

These two case studies indicate that the narratives identified in Ontario's pilot do indeed generalize more broadly to the creation and cancellation of other basic income projects. With this established, it is now time to identify a metanarrative that could bridge the gap between these two narratives so that basic income projects can be created without succumbing to the cancellation narrative. This new metanarrative is that the basic income project can reduce poverty without increasing taxes for the people. This metanarrative takes the previous narratives into account and creates a new narrative that accommodates both. How this metanarrative is fleshed out will be determined by both the design of the project it accompanies and how it is communicated to the public.

The project must be designed so that the money raised for basic income payments does not come from increasing the amount of taxes the people pay. Instead, covering the cost could come from (1) reallocating money from other parts of the government's budget, (2) increasing the corporate tax

\footnotetext{
${ }^{4}$ This fits in with the larger narrative sea change that was occurring in politics at the time from the welfare state to neoclassicalism.

${ }^{5}$ Those in the experimental group were healthier, less stressed, more focused, and more trusting of institutions, compared to the control group (Ministry of Social Affairs and Health, 2019, p. 30).
} 
rate, and/or (3) instituting a wealth tax. A government could reallocate funding from areas that have seen decreases in their expenditures as a result of the basic income project. For instance, decreases in healthcare costs, criminal justice costs, and public sector salaries are often cited as likely outcomes of a well-designed basic income program. Instituting a wealth tax would indeed represent a tax increase, but only for a small minority of taxpayers. The majority of taxpayers would not see a raise in their taxes, and thus, it would not be a tax increase for 'the people'. The public's understanding of the project's design is contingent on the successful communication of the metanarrative that validates it.

Part of the problem with the Ontario basic income pilot was that the government did not communicate where the funding for the payments was coming from. Nowhere in the official news release or in the 2016 or 2017 Ontario budgets was a pilot cost articulated let alone a cost figure for the Ontarian taxpayer. This left the pilot susceptible to the claim that its cost was "extraordinary" and that it would raise HST from "13 per cent to 20" (Ontario, 2018). The creation narrative had not set up anything to counter this cancellation narrative so the latter narrative could unfold unchallenged. It is for this reason that it is important for future basic income projects to explain clearly how they are funded. If the public understands that they will not be paying the price for reducing poverty, then a cancellation narrative will not sway them.

This is only a first pass at how a basic income project could be designed and communicated using the metanarrative. There are many ways ${ }^{6}$ to design a metanarrative-guided basic income project and there are many ways to communicate its narrative. The crucial insight to draw is that, however the project is designed and communicated, it should follow the metanarrative outlined in this paper. If it does not, then-like Ontario, Manitoba, and Finland's pilots-it could be undone by the cancellation narrative.

To summarize, the narrative that has been used to validate the creation of basic income projects is flawed because it is vulnerable to the cancellation narrative. The metanarrative is not vulnerable to the cancellation narrative, and consequently, it should be used by policymakers moving forward. This argument was advanced through a multi-step analysis. First, the creation and cancellation narratives were drawn out of the Ontario basic income pilot and then supported by the detection of these same narratives in Manitoba's Mincome project and Finland's basic income experiment. Next, it was proposed that a metanarrative-which reconciles the creation and cancellation narratives-could be used to advance a more resilient basic income project in the future. Developing a program steeped in this metanarrative is a tall order. Only a rough sketch of the design and communication of such a program has been attempted here. This paper has laid out the metanarrative that could have prevented Ontario's basic income pilot from failing, perhaps with further research it can be used to propel the next one to success.

\section{References}

"Costing a National Guaranteed Basic Income Using the Ontario Basic Income Model." Parliamentary Budget Office. April 17, 2018. https://www.pbodpb.gc.ca/en/blog/news/Guaranteed Basic Income

Crowley, Brian and Sean Speer. A Work and Opportunity Agenda for Canada. Macdonald-Laurier Institute, September 2018. https://macdonaldlaurier.ca/files/pdf/MLI GAI Labour FinalWeb.pdf

Crowley, Brian and Sean Speer. "Why Ontario was Right to Cancel the Basic Income Project." Toronto Sun, October 8, 2018. https://torontosun.com/opinion/columnists/crowley-and-speerwhy-ontario-was-right-to-cancel-the-basic-income-project

"EI Regular Benefits - Eligibility." Canada, 2019. https://www.canada.ca/en/services/benefits/ei/eiregular-benefit/eligibility.html

${ }^{6}$ For instance, if the project is structured as a universal basic income, then it might be permissible to raise taxes on a larger selection of the population as long this tax raise is less than the amount those people receive from basic income. 
Farthing, Brian. Social Experiments and Social Policy Formulation: A Study of the Manitoba Annual Income Experiment. PhD Thesis, August, 1991. http://etheses.Ise.ac.uk/1163/1/U048582.pdf

Forget, Evelyn. "The Town with No Poverty." Canadian Public Policy. University of Toronto Press, September, 2011.

Goodman, Peter. "Finland Has Second Thoughts About Giving Free Money to Jobless People." NY Times, April 24, 2018.

https://www.nytimes.com/2018/04/24/business/finland-universal-basicincome.html?action=click\&module=RelatedCoverage\&pgtype=Article\&region=Footer

Hum, Derek and Wayne Simpson. "Whatever Happened to Canada's Guaranteed Income Project?" Canadian Public Administration. September, 1993.

Legislative Assembly of Manitoba. April 5, 1979. https://www.gov.mb.ca/legislature/hansard/31st 3rd/hansardpdf/34b.pdf

Malling, Eric. "Liberal's Ignore Poor's Plight: Croll.” Toronto Star. p. A8, September 13, 1973.

Marinescu, loana. "No Strings Attached: The Behavioral Effects of U.S. Unconditional Cash Transfer Programs." The Roosevelt Institute. May 11, 2017. https://rooseveltinstitute.org/nostrings-attached/

"Ontario Basic Income Project." Ontario, April 24, 2017. https://www.ontario.ca/page/ontario-basicincome-pilot

"Ontario's Government for the People Announces Compassionate Wind Down of Basic Income Research Project." Ontario, August 31, 2018

https://news.ontario.ca/mcys/en/2018/08/ontarios-government-for-the-people-announcescompassionate-wind-down-of-basic-income-research-projec.html

Segal, Hugh. "Finding a Better Way: A Basic Income Pilot Project for Ontario." Ontario, August 31, 2016. https://www.ontario.ca/page/finding-better-way-basic-income-pilot-project-ontario 